\title{
A PROFESSIONAL'S GUIDE TO MOUTHWASH
}

The Oral Health Foundation has partnered with Johnson \& Johnson, the makers of LISTERINE, to create and publish The Dental Professional's Guide to Mouthwash Use.

The new six-page guide has been created as a plaque management tool for you to help patients take control of their own oral health at home.

The booklet covers the role of mouthwash as part of the daily oral health routine, as well as recommendations for mouthwash use based on the latest available evidence.
According to recent research by the Oral Health Foundation, almost half (49\%) of the survey participants do not use mouthwash regularly while more than one in three (36\%) never use it.

The toolkit contains advice about changing patient behaviour to increase their probability of adopting daily mouthwash use at home. It also includes information about the different types of mouthwash available and its role within plaque management.

The Dental Professional's Guide to

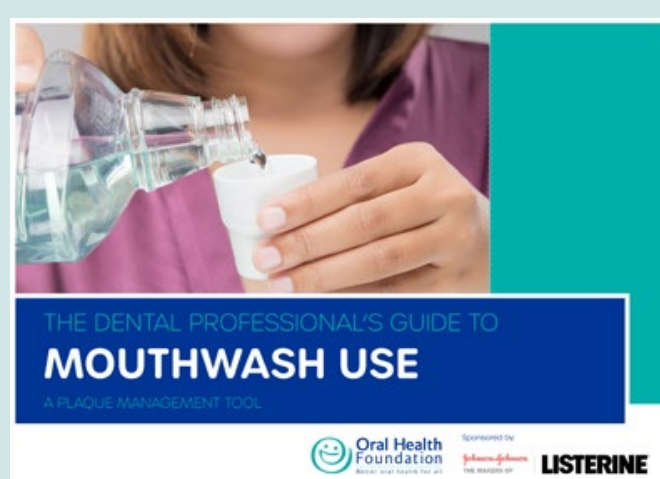

Mouthwash Use can be downloaded from the charity's website: https://www. dentalhealth.org/the-dental-professionalsguide-to-mouthwash-use.

\section{BESPOKE ADVICE ON AIR PURIFICATION}

Plain Air advises a range of businesses on keeping their premises COVID-19 secure. They provide an independent advice service so that dentists can obtain their preferred air purification solution quickly, with no disruption to services.

According to Plain Air, the cost of installing suitable equipment is often less than the fees earned in a single day, and being able to close the windows, reduce heating costs and keep the temperature comfortable in the practice is especially valuable.

Plain Air has dedicated its time to understanding everything about air pollution and COVID, and know that only a minority of products come close to meeting their advertised specifications. Plain Air only recommends products that it know will do the job and will continue to do so for years to come. For more information visit https:// www.plainair.co.uk/.

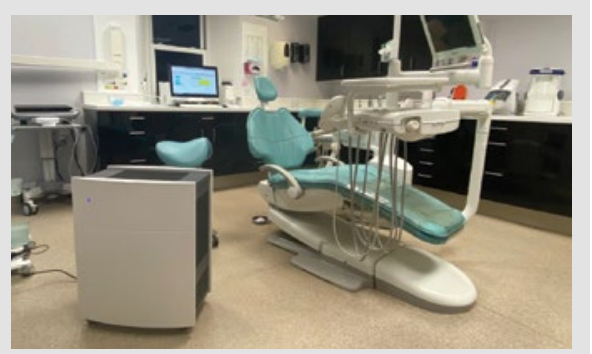

\section{GETTING BACK TO IN-PERSON LEARNING}

When it is safe to do so, the benefits of hands-on training and in-person learning cannot be beaten. Don't miss your chance to develop your skills at the British Dental Conference and Dentistry Show 2021 - on Friday 25 and Saturday 26 June - where you will have access to hours of enhanced CPD and live demonstrations.

There will be conference streams dedicated to each area of the profession, with worldclass speakers sharing their expertise on a wide range of topics. The extensive trade floor will also host a dynamic selection of dental manufacturers and suppliers with innovative technologies and materials to discover.
Delegates will be able to interact with thousands of colleagues, friends, product specialists and renowned figures at the very forefront of their respective fields.

To get back to quality in-person learning, don't miss the British Dental Conference and Dentistry Show 2021!

The British Dental Conference and Dentistry Show 2021 will be held on Friday 25 and Saturday 26 June, Birmingham NEC, co-located with DTS.

For more information on the event, visit www.thedentistryshow.co.uk, call 0207348 5270 or email dentistry@closerstillmedia. com.

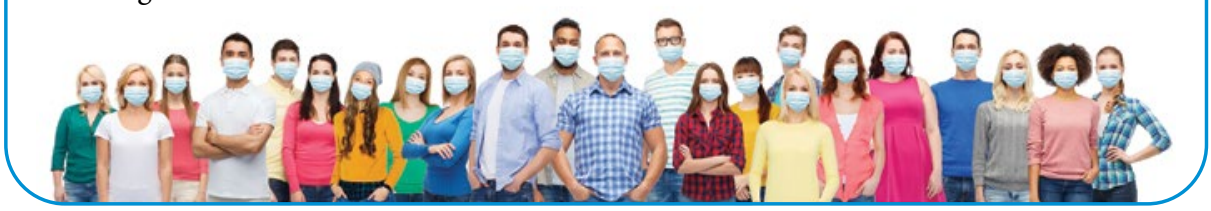

THE GAMECHANGING COVID-19 ANTIBODY TEST

Screening your dental team for COVID19 is quick and effective with the BioSURE COVID-19 Triple Antibody Rapid Test. It is simple to perform and only requires $5 \mathrm{ul}$ of capillary blood to deliver results in just ten minutes.

Developed and manufactured in the $\mathrm{UK}$, this test comes in a box - priced at $£ 750$ excluding VAT - that contains sufficient product for 25 tests ( $£ 30$ per test). Take full advantage of this game-changing solution with the help of leading oral health specialist, Curaden.

The team can support you with:

n High-quality PPE

- Educational resources

- Comprehensive training for your COVID-19 screening staff

- Creating a socially distanced screening area in your practice

- Reporting tools in the form of the BioSURE powered by PocDoc app.

To order, call 01480 862084, email info@curaprox. co.uk or visit www.curaprox. co.uk.

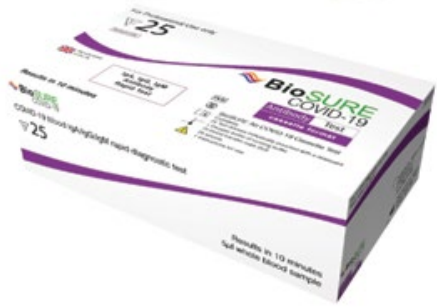

If you would like to promote your products or services direct to the dental industry in BDJ Team, call Andy May on 02078434785 or emaila.may@nature.com 